\title{
A ANGÚSTIA COMO FORMA DE LEITURA: OS DILEMAS (DOS) INTELECTUAIS
}

\author{
Vera Lucia Bianco ${ }^{*}$ \\ Universidade Federal de Santa Catarina
}

Este texto é resultado das inúmeras leituras de um texto de Walter Mignolo, intitulado "Posoccidentalismo: las epistemologias fronterizas y el dilema de los estudios (latinoamericanos) de areas".

Ao começar a lê-lo, deparei-me com uma dificuldade muito grande de enfoque. Por onde deveria começar, o que deveria privilegiar? Minha angústia foi crescendo à medida em que crescia o resumo que fazia do texto, resumo sendo a única coisa que eu conseguia fazer. E que de resumo não tinha nada, posto que ficava cada vez maior do que o original. Até que me dei conta de que minha angústia era o reflexo da angústia do autor, presente nas questões que o texto levanta. $\mathrm{O}$ artigo discute a questão da produção do saber e do lugar onde se produz esse saber, bem como da comunidade de recepção do texto. Discute ainda a questão da americanidade e, consequentemente, da inserção da América no concerto planetário, nas palavras de Mignolo. Mas, apesar da forma bastante acadêmica do artigo, havia um "eu" muito presente no texto, um "eu" que discutia sua posição e sua produção, e cuja angústia transparecia e me contaminava. Minha dificuldade de pensar sobre o texto se devia, pois, ao fato de pretender refletir sobre o que não era central na discussão. A única saída era então concentrar-me na angústia que eu lia.

Vamos pelo começo. De que e de onde está falando Mignolo? Como escreve e para quem escreve? Argentino, trabalhando em Duke, nos Estados Unidos, produz textos em espanhol e em inglês, publicados em revistas norte-americanas e latino-americanas. Dialoga

Esta obra está licenciada sob uma Licença Creative Commons.

\footnotetext{
* Doutoranda em Literatura pela Universidade Federal de Santa Catarina (in memoriam).
} 
com intelectuais latino-americanos, latino-americanos do norte e americanos. Seu texto segue os parâmetros dos "papers" americanos, plenos de citação e indicações bibliográficas, um texto que é um pensar dentro das regras acadêmicas da produção americana e internacional, longe do ensaio, que ele próprio define como "o espaço adequado para um pensar às margens das disciplinas", como forma de as regiões menos desenvolvidas poderem competir ou se manter no mesmo nível na produção de conhecimentos, posto que a prática acadêmica e científica se assenta nas regiões de grande desenvolvimento econômico e científico. Assim, Mignolo escreve segundo as normas da comunidade reguladora da produção intelectual e não às margens do pensar disciplinado. Mais ainda, está em Duke, produzindo dentro das estruturas de produção do imperialismo, sendo parte de um departamento que estuda a alteridade - como conciliar estes dois mundos e ser um pensador latino-americano? Isso provoca angústia.

Neste texto específico, Mignolo discute a questão dos intelectuais e acadêmicos no mundo de hoje. Começa colocando a proposta de Fernandez Retamar em um artigo de 1976 e uma proposta de Fernando Coronil, vinte anos depois, em 1996, sobre a necessidade de uma reconfiguração das categorias geoculturais e epistemológicas que tradicionalmente organizaram nosso mundo em um mundo ocidental. Partindo da ocidentalização do mundo, com a sua criação do orientalismo como estratégia de sua própria construção e manutenção, Mignolo discute a questão do americano, da América Latina e da possibilidade da construção de histórias locais. Fomos, na América do Sul, primeiro definidos como ocidentais, a partir do rótulo de índias Ocidentais. Gradualmente, passamos a ser o Novo Mundo e chegamos a "Nuestra America" ou América, rótulo que nos coloca na posição de referência não do colonialismo ou da colonização, mas na referência do ocidentalismo ou de ocidentalização, que tentamos superar hoje.

Mas quem é esse "nós", que identidade é essa, o que é hoje o "latino-americano verdadeiro", como colocava Retamar em 1976, e que ele julgava possível definir como um "nãoeuropeu", ou seja, um não ocidental, uma minoria nacional que constitui uma maioria real? (Podemos aqui pensar o deserto como uma região ocupada por uma cultura que não é reconhecida como tal, citando Beatriz Sarlo, e avançar na discussão da "desertificação" de áreas cada vez maiores da América do Sul). Mas, pergunta Mignolo, o que é um latinoamericano, um não-europeu, em um mundo transnacional, que já não permite mais que se estabeleçam relações entre cultura e território? A coisificação do conceito de cultura e a gestação de entidades como as culturas nacionais foi e é parte integrante da própria ideia de 
ocidentalismo, da construção do ocidente como o eu-mesmo e do resto do planeta como a alteridade. Donde a cultura ser pensada como entidade fechada em territórios nacionais.

A América Latina é uma entidade geocultural criada por projetos imperialistas, que foi se configurando conflitivamente no próprio processo de ocidentalização. Hoje, a transnacionalização do capital fratura cada vez mais a ideia de identidade entre cultura e território, que acarreta a fratura dessa entidade, $\mathrm{AL}$, fundada pelo discurso imperialista da modernidade, que funda estruturas de poder sobre o princípio da "pureza do sangue e da unidade da língua" (os três genocídios da modernidade). Assim, pensar a AL é pensar a superação desse modelo ocidentalista e transcender as repressões forjadas e surgidas das expansões coloniais, superação possível se mantivermos o pós-ocidentalismo como horizonte.

Pós-ocidentalismo pode então designar a reflexão crítica sobre a situação histórica da AL que emerge durante o século19, quando vão se definindo as relações com a Europa e se vai gestando o discurso da "identidade latino-americana", passando pelo ingresso dos EUA no rol das potências mundiais, até a situação atual, na qual o termo adquire uma nova dimensão devido ao ingresso do capitalismo no "Oriente". (O autor define como "Oriente" o leste e o sudeste da Ásia, neste texto de 1996, mas claro que hoje, três anos depois, devemos incluir a antiga União Soviética como o talvez mais ocidentalizado dos países “orientais”).

Outro ponto importante no texto é quanto ao papel dos intelectuais e acadêmicos no mundo de hoje, quando a teoria perdeu sua força de ditadora da prática, e portanto os intelectuais perderam seu papel de condutores das massas, lembrando Marcuse nos idos de 68. Os movimentos sociais cresceram em número e diversidade, diz Mignolo, e já não podemos pensar apenas o proletariado como movimento de força e de transformação social, como advogavam os intelectuais marxistas ou gramscianos, mas todas as classes oprimidas podem ser transformadoras das relações sociais. Então, se os intelectuais correm o risco de desaparecer, por total ausência de papel, é porque eles mesmos estão se convertendo em um movimento social, ou estão inseridos em outros movimentos sociais, de tipo étnico, sexual, ambiental, etc. Isso faz com que seu papel de intelectual se minimize ou desapareça, na medida em que esses movimentos sociais teorizam a partir de sua prática e não de teorias que são impostas de cima para baixo, "como nos tempos de Stalin e dos gulags, que mostram como a teoria pode converter-se em força material de controle e de justificação de decisões". Nessa medida, a rearticulação das relações entre práticas sociais e práticas teóricas é um aspecto fundamental do pós-ocidentalismo como condição histórica e horizonte intelectual. Pós-ocidentalismo concebido como projeto crítico e superador do ocidentalismo, que foi o 
projeto pragmático das empreitadas colonizadoras nas Américas desde o século 16, desde o colonialismo espanhol até o norte-americano e o soviético.

A discussão sobre estes assuntos ocorre em um momento de grande efervescência na AL, afirma Mignolo, um momento de grande produção intelectual, que tende a perder-se na cena internacional por causa da força hegemônica do idioma inglês e da discussão em torno do pós-modernismo e do pós-colonialismo, fundamentalmente travada em inglês.

Aqui, quero destacar dois pontos que, me parece, angustiam Mignolo. O primeiro diz respeito a como eu me defino, a qual grupo étnico pertenço. E, pour cause, em que língua devo escrever: em inglês, para me encaixar no discurso universal, conseguir ser publicado e circular pelos meios acadêmicos e intelectuais, podendo, desta forma, fazer circular meu discurso? Ou devo escrever em minha língua menor, no caso o espanhol, correndo o risco de ser lido apenas pela minha comunidade?

E então chegamos a dois outros problemas: o do discurso produzido na ou sobre a América Latina e o dos estudos de área. Diz Mignolo:

\begin{abstract}
O cenário da produção intelectual na AL no período entre os anos 60 e 70 foi dominado pelas teorias de dependência e de colonialismo interno, teorias que são, à sua maneira, reflexões pós-ocidentais, na medida em que buscam projetos que transcendam as dificuldades e os limites do ocidentalismo. São projetos que levam o nome de "desenvolvimento", não mais de "cristianização" ou de "missão civilizadora". Mas esta história tende a integrar-se a outra, à dos estudos de área. Nessa operação, uma dramática colonização intelectual se processa: a AL deixa de ser o lugar onde se produzem teorias para continuar a ser o lugar que se estuda. [...]. É uma mudança de olhar que converte a AL em uma área para ser estudada, mais do que um espaço onde se produzem conhecimentos.
\end{abstract}

Não um sujeito que opera o saber e sim objeto do saber, nos termos da teoria da dependência.

Como alterar essa perspectiva, eis a questão. Apoiando-se em Coronil, em um artigo de 96 intitulado "Beyond Occidentalism: toward post-imperial geocultural categories", Mignolo reflete sobre o problema de transcender as categorias geo-culturais que configuram a AL como espaço dos projetos imperialistas, mantendo as categorias da epistemologia moderna e transcendendo-as na integração do que elas mesmas negam. Leiamos com Coronil:

\footnotetext{
"Beyond" aqui deve ser entendido no plano das categorias geoculturais, um transcender tais categorias, mantendo as da epistemologia moderna, e transcendê-las na investigação do que elas mesmas negaram. Assim, civilização e barbarie - a incorporação da barbarie nos termos negados pela civilização permite transcendê-la, não reivindicando seu oposto, mas sim a força da barreira que cria a possibilidade da barbárie de negar-se como barbárie na alteridade, isto é, revelar a barbárie no seu próprio que a civilização ocultou. Ou seja, a geração de uma epistemologia de fronteira a partir de vários espaços/lugares do Terceiro Mundo, configurado por
} 
diferentes heranças coloniais, para o conhecimento e a civilização planetária. Não uma epistemologia para os marginais, ou do Terceiro Mundo para o Terceiro Mundo, que mantém a hegemonia e a universalidade do conhecimento produzido no não-lugar e na objetividade dos projetos imperialistas.

Coronil parece encarar aqui o dilema de Mignolo na sua totalidade: como gestar uma epistemologia de fronteira quando se está integrado na comunidade acadêmica de um projeto imperialista; como produzir conhecimento no Terceiro Mundo e não sobre o Terceiro Mundo, nessas circunstâncias?

Demonstrando que cultura e território não podem mais existir como parte do constructo social da história dos povos, dado o grau de transnacionalização do universo, Mignolo discute a rearticulação das categorias de história e geografia, tempo e espaço, memória e localização. Partindo do fato de que as categorias históricas e geográficas são práticas disciplinares que sustentam as estruturas de poder, sua rearticulação passaria pelo repensar a conceitualização de América Latina no momento em que novas regiões são construídas, como o Mercosul e o Nafta, não esquecendo a força que o Caribe está adquirindo nos projetos transnacionais. Com a polarização das classes sociais a nível mundial, a migração em massa, o crescente tecnoglobalismo, etc, as categorias familiares são desenraizadas de seus lugares originais e ligadas a novas locações. O espaço se torna fluido, e portanto a história não pode ser ancorada em territórios fixos. Essa desterritorialização leva a uma nova territorialização, mas torna mais visível o constructo social de espaço, cujo congelamento constantemente se associa a congelamento histórico. O Outro não é mais mantido em espaços confinados, e as identidades coletivas estão sendo definidas em lugares fragmentados, que não podem mais ser mapeados com categorias antiquadas. A entrada no concerto mundial do oeste asiático torna cada vez mais difícil manter a bipolarização “ocidente e o resto".

A questão então é: como transcender o ocidentalismo, construindo categorias geohistóricas que não sejam imperialistas? Para Coronil, a questão passa por rearticular história e geografia como categorias que organizam o mundo temporal e geograficamente, de forma a deslocá-las enquanto disciplinas que mantêm as estruturas de poder, gerando o apagamento das histórias locais e a subordinação à história universal do Ocidente, mas também estabelecendo novas categorias geo-históricas, que desalojem as construídas pela modernidade. No atual mundo globalizado, a questão da alteridade perde relevância e começa a ser substituída por estruturas econômicas globais e políticas trans-estatais, que tornam mais visível a questão da subalternidade, que ultrapassa os marcos sociais e cria condições para a multiplicação de movimentos sociais e para a rearticulação da sociedade civil. 
É necessário então, diz Mignolo, repensar a conceitualização de AL que Retamar revisa e ordena, no momento em que as utopias socialistas caíram, o capital internacional começa a construir novas regiões (Mercosul, Nafta), o Caribe ganha terreno nos projetos transnacionais para a América do Sul, e as migrações corroem os supostos laços de cultura e território. É preciso também repensar as ligações entre pensamento latino-americano e estudos latino-americanos no âmbito da produção intelectual e acadêmica. Construir a AL no novo cenário global significa construir aponte entre pensamento na América Latina e estudo da América Latina. Como não continuar reproduzindo o modelo dos estudos de área e passar a uma perspectiva crítica de pensamento baseada na perspectiva pós-ocidentalista?

Retomando o já visto, a prática literária e filosófica, o ensaio, foi e é o espaço onde nasceu e se manifestou um "pensar" às margens das disciplinas. Isso se explica porque, na medida em que a prática acadêmica e científica (ciências sociais) se assenta e se baseia nas regiões de grande desenvolvimento econômico e tecnológico, as regiões de menor desenvolvimento não podem competir ou manter-se no mesmo nível na produção de conhecimentos. Então, o trabalho intelectual acadêmico se divide em zonas onde se produz “conhecimento" sobre certas regiões ou áreas e zonas nas quais se produz "cultura”.

$\mathrm{Na}$ organização do mundo promovida pela ocidentalização, as ciências se articularam em determinadas línguas e localidades geográfico-epistemológicas. Para além das ciências sociais, ficaram as práticas de pensamento. Assim, a reorganização da produção do conhecimento em uma perspectiva pós-ocidentalista teria que ser formulada em uma epistemologia fronteiriça, na qual a reflexão (filosófica, literária, ensaística) incorporada às histórias locais encontra seu lugar no conhecimento des-incorporado dos projetos globais em ciências sociais. Uma epistemologia fronteiriça, pós-ocidental, que permita pensar e construir um pensamento a partir dos interstícios e aceitar que os imigrantes, os refugiados, os homossexuais etc são categorias fora da lei, do ponto de vista de uma epistemologia monotópica, que normatiza determinados espaços (nacionais, imperiais) como espaços de contenção e marginalização.

Voltando ao início, a grande angústia reside neste ponto, o ser capaz de contribuir para a reestruturação das categorias geográfico-epistemológicas de maneira a não reproduzir ou sustentar as estruturas de poder imperialista que configuram a AL como área onde se produz cultura.

Parece-me que o texto de Mignolo aponta para as mesmas angústias que Idelber Avelar e Alberto Moreira expressaram no último Congresso da Abralic. Avelar começa sua 
intervenção discutindo a dissolução da Universidade na universalidade do mercado, passando a discutir o papel do intelectual e suas relações com o Estado. Moreira fala da crítica de colonialistas aos latinistas dos estudos culturais e da crítica dos latino-americanos aos "latinoamericanos do norte", mantendo a fronteira entre sul e norte, entre a AL e a outra América, sobre quem escreve e quem pensa, um discurso que se conclui com uma frase muito forte: o norte não é todo norte, nem o sul é todo sul. Nos três discursos, leio a angústia do intelectual latino-americano no norte lutando contra a possibilidade de ser convertido em um latinoamericano do norte.

[Este artigo teve sua primeira publicação no n. 6, 1998, da Anuário de Literatura]

\section{Nota}

1. Walter Mignolo. "Posocidentalismo: las epistemologias fronterizas y el dilema de los estudios (latino americanos) de áreas". Revista Iberoamericana, v. LXII, n 176-177, JulioDiciembre 1996. pp. 679-696.

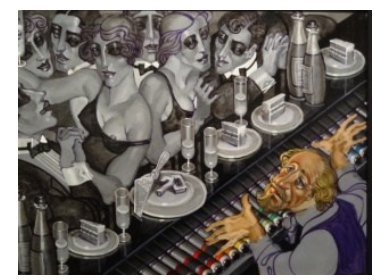

